\title{
Chromatographic Fingerprint Analysis of Hydro- alcoholic extract of Medicinally Important plant Elephantopus scaber I. Using HPTLC Technique
}

\author{
Ravindra Hiremath ${ }^{1,2}$, Sunil Jalalpure ${ }^{* 1,2}$, Shriram Pethakar ${ }^{3}$ \\ 1'Department of Pharmacognosy, K.L.E. University's College of Pharmacy, Belagavi-10, Karnataka, INDIA. \\ ${ }^{2}$ Prabhakar Kore Basic Science Research Center, K.L.E. University, Belagavi-10, Karnataka, INDIA. \\ ${ }^{3}$ Department of Pharmaceutical Biotechnology, KLE University's College of Pharmacy, Belagavi-590010, Karnataka, INDIA.
}

\begin{abstract}
Objective: To develop chemical fingerprint profile of secondary metabolites of therapeutically important plant Elephantopus scaber L. using HPTLC technique. Method: Preliminary phytochemical investigation was performed for the detection of secondary metabolites. HPTLC fingerprint profile of hydro-alcoholic extract of $E$. scaber was developed for alkaloids, flavonoids and saponins. Toluene: Ethyl acetate: Diethyl amine (7:2:1), Ethyl acetate: Formic acid: Glacial acetic acid: Water (10:0.5:0.5:1.3) and Chloroform: Acetic acid: Methanol: Water (6.4:3.2:1.2:0.8) were the solvent systems developed. Results: The HPTLC chromatogram of hydro-alcoholic extract of $E$. scaber resolved 12 alkaloids, 25 flavonoids and 26 saponins with different $\mathrm{Rf}$ values including some unknown. Conclusion: Chemical profiling of selected plant is suggestive of several known and unknown bioactive molecule having potential therapeutic efficacy. The unknown alkaloids, flavonoids and saponins separated needed to be elucidated further. It can be concluded that the HPTLC fingerprint analysis is useful in exact identification of plant material. Also, it serves as a significant tool in differentiating adulterants and biomarker in herbal drug industry.
\end{abstract}

Key words: HPTLC Fingerprinting, E. Scaber, Chromatograms, Biomarker, Rf value.

\section{INTRODUCTION}

Herbal medicines have been in use since ancient days for treatment and management of human ailments. Traditional system of medicine over the years has gained a wide acceptance worldwide. Associated undesired effects and economic constraints with the modern medicine drive us for search of potent drug from natural resources. Therapeutic efficacy of drugs of plant origin solely depends upon the authenticity and purity of plant material. A major key factor in efficacy of herbal products resides in assurance of safety and quality. Hence, phytochemical standardization and evaluation is need of the hour.
Fingerprinting (FP) approach has been recently recognized and accepted for quality assessment of traditional medicines. The concept of phyto equivalence was developed to ensure consistency of herbal products. According to this concept, a chemical profile, such as chromatographic fingerprint, for herbal product, should be constructed and compared with the profile of a clinically proven reference product. ${ }^{1}$

Different methods are used for FP which may be roughly categorized as (i) Low resolution techniques like TLC or IR-based methods (ii) High resolution techniques like GC, HPLC, MS, NMR or hyphenated techniques and are commonly accepted as well
Submission Date : 04-08-2016 Revision Date : 31-08-2016 Accepted Date : :09-09-2016

DOI: 10.5530/ijper.50.4.21 Correspondence:

Dr. Sunil S. Jalalpure, Deputy Director,

Dr. Prabhakar Kore Basic Science Research Center, K.L.E. University, Belagavi-10, Karnataka, INDIA.

Tel: +91-831-2471399 (Office),

(Fax), +91-831-2472387 (Mobile) +91-9448964057 E-mail : jalalpuresunil@ rediffmail.com

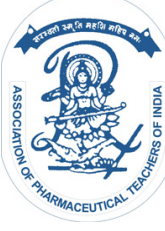

www.ijper.org 
suited for FP aiming at a comprehensive extract characterization. $^{2}$

Fingerprint analysis by HPTLC is useful as phytochemical markers and also as good estimators of genetic variability in plant populations. It is becoming routine analytical technique because of the advantages of small amount of mobile phase needed, speed, and simultaneous estimation of several samples unlike HPLC. ${ }^{3}$ HPTLC finger printing is proved to be a linear, precise, accurate method for herbal identification and can be used further in authentication and characterization of medicinally important plants. ${ }^{4}$ Significant application of HPTLC was found to be useful in determination of adulteration in raw material as well as finished goods, identification of substitutions of botanicals in place of official ones and in comparing the same extracts with different batches and same species with varied populations collected from different demographic regions. Due to advancement in technology HPTLC is the preferred tool in analysis of various natural products. ${ }^{5}$

Elephantopus scaber A perennial rigid herb found in dry localities. Plant pacifies vitiated vata, pitta, toxins, cough, and cardiac ailments. As per traditional claims, the roots are used as an antipyretic, cardio tonic and diuretic. ${ }^{6}$ Decoction of the roots and leaves is used as emollient and given in dysuria, diarrhea, dysentery and stomach pain. ${ }^{7}$ Aqueous extract of leaves is applied externally to treat eczema and ulcers. ${ }^{8}$ Roots are used in the treatment of Kidney stone. ${ }^{9}$ In the present study fingerprint analysis of hydro-alcoholic extract of E. scaber was carried out for chemical profiling of the secondary metabolites present in it.

\section{MATERIALS AND METHODS}

\section{Collection of plant material}

The selected Indian medicinal plant Elephantopus scaber Linn was collected from the forest Jamboti, 40 $\mathrm{km}$ away from Belagavi, Karnataka, India and authenticated by Dr. Harsha Hegde, Scientist B, RMRC, ICMR, Belagavi. The herbaria was prepared and stored (Voucher Specimen Numbers RMRC-914) at RMRC, ICMR, Belgaum, Karnataka.

\section{Extraction}

The shade dried plant was processed for size reduction and sieved through sieve no.40 to get a coarse powder. Further, extraction was carried out by continuous hot extraction process using ethanol and water (70:30) as solvent for 8-10 hrs. The extract was concentrated using rotary evaporation technique (IKA Rotary Evaporator) at $40^{\circ} \mathrm{C}$ to give a syrupy mass. This was stored in a closed container and used for analysis.

\section{Preliminary Phytochemical Investigation}

Preliminary phytochemical analysis for the determination of presence of alkaloids, flavonoids, saponins, tannins, triterpenoids, carbohydrates, glycosides and steroids was carried out. ${ }^{10-13}$

\section{Solvent System (Mobile Phases) Development}

Confirmation of presence of these phyto constituents was done by developing a thin layer chromatographic profile. Different solvent systems with varying polarity and proportions were tried for better separation and resolution.

\section{HPTLC analysis}

HPTLC fingerprinting was carried out using pre-coated silica gel aluminum plates (E. Merck, Darmstadt, Germany). Thus developed spots were identified by spraying various indicator reagents. HPTLC test solution was prepared by dissolving $100 \mathrm{mg}$ of hydro-alcoholic extract of plant material in $5 \mathrm{~mL}$ of methanol, centrifuged (Eppendorf, Minispin Plus) at $3000 \mathrm{rpm}$ (493 x g) for 8 min. ${ }^{14,15}$

\section{Instrumentation}

Stationary phase $\quad$ : Plate size $(\mathrm{X} \times \mathrm{Y}) 20.0 \times 10.0 \mathrm{~cm}$ Precoated silica gel aluminum plates $60 \mathrm{~F}-254$

Instrument

: CAMAG Linomat 5

"Linomat5_080222" S/N

080222(1.00.12)

Linomat 5 application parameters

$\begin{array}{lll}\text { Spray gas } & : & \text { Inert gas } \\ \text { Sample solvent type } & : & \text { Methanol } \\ \text { Dosage Speed } & : & 150 \mathrm{~nL} / \mathrm{s} \\ \text { Pre-dosage Volume } & : & 0.2 \mu \mathrm{L}\end{array}$

Sequence

Syringe size $\quad: 100 \mu \mathrm{L}$

Number of tracks : 1

Band length $\quad: \quad 8.0 \mathrm{~mm}$

Application Volume : $5.0 \mu \mathrm{L}$

Measurement Table

Wavelength : $254 \mathrm{~nm} / 366 \mathrm{~nm} / 540 \mathrm{~nm}$

Lamp : D2

Detector Mode : Automatic

Development of chromatogram and detection of spots

Chromatogram was developed after application of the spots, in a twin trough glass TLC chamber previously 
Table 1: Preliminary phytochemical investigations of hydro-alcoholic extract of $E$. scaber

\begin{tabular}{|c|c|c|c|}
\hline \multirow{2}{*}{ Sr. No. } & \multirow{2}{*}{ Chemical component } & \multirow{2}{*}{$\begin{array}{l}\text { Name of the } \\
\text { chemical test }\end{array}$} & Results (Plant) \\
\hline & & & Elephantopus scaber $\mathbf{L}$ \\
\hline \multirow{3}{*}{1.} & \multirow{3}{*}{ Carbohydrates } & Molisch's test & + \\
\hline & & Benedict's test & + \\
\hline & & Fehling's test & - \\
\hline \multirow{5}{*}{2.} & \multirow{5}{*}{ Alkaloids } & Mayer's test & + \\
\hline & & Wagner's test & + \\
\hline & & Dragendroff's test & + \\
\hline & & Hager's test & - \\
\hline & & Tannic acid test & - \\
\hline \multirow{2}{*}{3.} & \multirow{2}{*}{ Phytosterols } & Salkowski test & + \\
\hline & & Libermann Burchard test & + \\
\hline \multirow{4}{*}{4.} & \multirow{4}{*}{ Glycosides } & Legal's test & - \\
\hline & & Liebermann's test & - \\
\hline & & Keller killiani test & - \\
\hline & & Xanthydrol test & - \\
\hline 5. & Tannins and Phenols & Ferric chloride test & + \\
\hline \multirow{2}{*}{6.} & \multirow{2}{*}{ Proteins } & Millon's test & + \\
\hline & & Ninhydrin test & + \\
\hline \multirow{3}{*}{7} & \multirow{3}{*}{ Amino acids } & Ninhydrin test & + \\
\hline & & Test for Tyrosine & + \\
\hline & & Test for Tryptophan & - \\
\hline \multirow{4}{*}{8} & \multirow{4}{*}{ Flavonoids } & Shinoda test & + \\
\hline & & Lead acetate test & + \\
\hline & & Alkaline solution test & - \\
\hline & & Ferric chloride test & + \\
\hline \multirow{2}{*}{9} & \multirow{2}{*}{ Triterpenoids } & Salkowaski test & + \\
\hline & & Liebermann Burchardt test & + \\
\hline 10 & Saponins & Frothing Test & + \\
\hline
\end{tabular}

saturated with respective solvent systems for $30 \mathrm{~min}$. The HPTLC plates were dried and photo documentation was done at UV 254, 366, $540 \mathrm{~nm}$ and daylight with Camag Repro star chamber; scanning was done and images were captured. Using win CATS Planar Chromatography Manager software; Rf values at fingerprint data were recorded.

\section{RESULTS}

Preliminary phytochemical investigations reveal the presence of alkaloids, flavonoids, terpenoids, steroids, saponins, and tannins in the hydro-alcoholic extract of E. scaber (Table 1).

To achieve reproducible peaks with high resolutions various combinations of different solvents in different proportions were tested. Satisfactory results were obtained with Toluene: Ethyl acetate: Diethyl amine
(7:2:1), Ethyl acetate: Formic acid: Glacial acetic acid: Water (10:0.5:0.5:1.3) and Chloroform: Acetic acid: Methanol: Water (6.4:3.2:1.2:0.8) for alkaloids, flavonoids and saponins respectively. The hydro-alcoholic extract of E. scaber showed presence of 12 alkaloids, 25 flavonoids and 26 saponins with different $\mathrm{Rf}$ values when scanned at 254, 366 and $540 \mathrm{~nm}$ wavelength (Table 2).

The HPTLC chromatogram showed 12 bands of alkaloids (Figure 1). Major alkaloids separated were observed at $R f$ value $0.06,0.11,0.13,0.18,0.32,0.41,0.48,0.57$ at $254 \mathrm{~nm} ; 0.19,0.73$ at $366 \mathrm{~nm}$ and $0.23,0.71$ at $540 \mathrm{~nm}$. One unknown alkaloid each at $366 \mathrm{~nm}$ (Rf-0.73) and at $540 \mathrm{~nm}$ (Rf- 0.23) was detected (Figure 2 and 3).

Total 25 flavonoids (Figure 1) were resolved satisfactorily with $\mathrm{Rf}$ values $0.17,0.23,0.30,0.33,0.40,0.47,0.61$, $0.66,0.73,0.78$ at $254 \mathrm{~nm} ; 0.15,0.20,0.26,0.71,0.74$, 


\begin{tabular}{|c|c|c|c|c|c|c|}
\hline \multirow[t]{2}{*}{ Peak \# } & \multicolumn{2}{|c|}{ Wavelength 254} & \multicolumn{2}{|c|}{ Wavelength 366} & \multicolumn{2}{|c|}{ Wavelength 540} \\
\hline & Identified & Unknown & Identified & Unknown & Identified & Unknown \\
\hline Alkaloids & 8 & 0 & 2 & 1 & 2 & 1 \\
\hline Flavonoids & 10 & 0 & 6 & 2 & 9 & 4 \\
\hline Saponins & 9 & 0 & 6 & 2 & 11 & 2 \\
\hline
\end{tabular}

0.81 at $366 \mathrm{~nm}$ and $0.15,0.23,0.25,0.49,0.58,0.62$, $0.74,0.76,0.80$ at $540 \mathrm{~nm}$. Two unknown flavonoids at $366 \mathrm{~nm}$ (Rf- 0.15 and 0.74 ) and four at $540 \mathrm{~nm}$ (Rf$0.23,0.58,0.74$ and 0.76 ) were detected (Figure 4 and 5). HPTLC chromatogram for saponins (Figure 1) exhibited 26 bands with the $\mathrm{Rf}$ values $0.10,0.14,0.21,0.30$, $0.35,0.46,0.55,0.68,0.78$ at $254 \mathrm{~nm} ; 0.10,0.23,0.36$, $0.47,0.65,0.76$ at $366 \mathrm{~nm}$ and $0.12,0.15,0.16,0.23$, $0.27,0.33,0.38,0.43,0.50,0.59,0.71$ at $540 \mathrm{~nm}$. Total four saponins i.e two at $366 \mathrm{~nm}$ (Rf- 0.47 and 0.65 ) and $540 \mathrm{~nm}$ (Rf- 0.12 and 0.33) each was detected (Figure 6 and 7).

\section{DISCUSSION}

Natural products are proven to be the major source of bioactive compounds and served as a significant tool in discovery of many lead compounds for management and treatment of human ailment. They truly play a vital role in field of drug discovery and development. ${ }^{16}$ Screening and evaluation of herbal drugs becomes an integral part towards their exact identification and standardization. Numerous analytical tools and techniques were developed for quality control of plants and plant products. HPTLC fingerprinting has potential to verify and determine the reliability of secondary metabolites in natural resources and their formulations as well. ${ }^{17}$ HPTLC Fingerprint analysis facilitates the assessment of quality and stability of plant material and their products by visual and standardized fingerprint profile comparison. Present study was intended to screen hydro-alcoholic extract of E. scaber for the presence of secondary metabolites and development of fingerprints by HPTLC Technique. Alkaloids, flavonoids and saponins are the bioactive constituents having significant therapeutic value and pharmacological properties. The quality and quantity of these secondary metabolites in plant resources varies depending upon the region, demographic location and time of collection of the plant material as well as plant part or tissue used..$^{18}$ In present study, the hydro-alcoholic extract of E. scaber showed presence of different alkaloids, flavonoids and saponins with different $\mathrm{Rf}$ values, area, intensity and

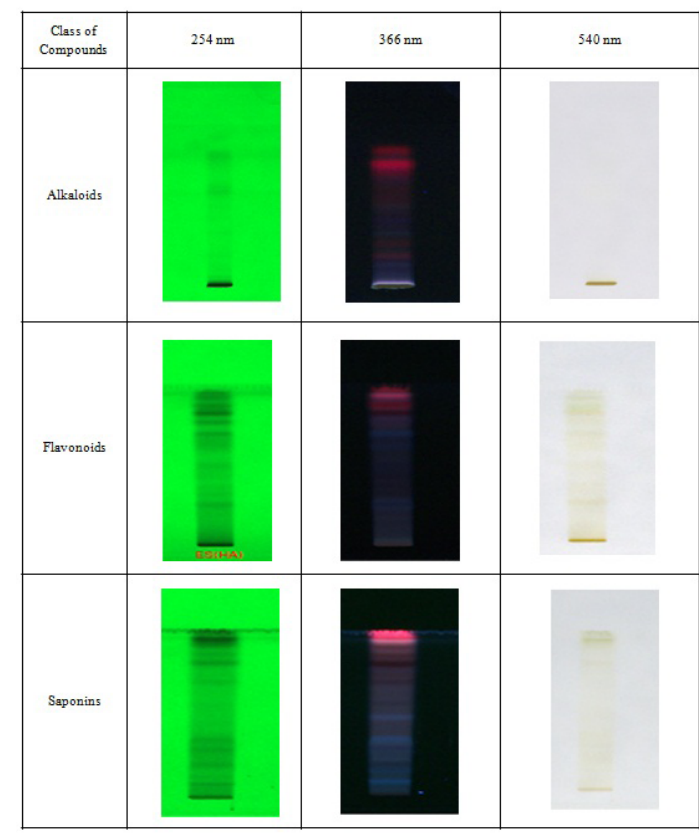

Figure 1 : Images of HPTLC chromatograms of hydro-alcoholic extracts of $E$. scaber.

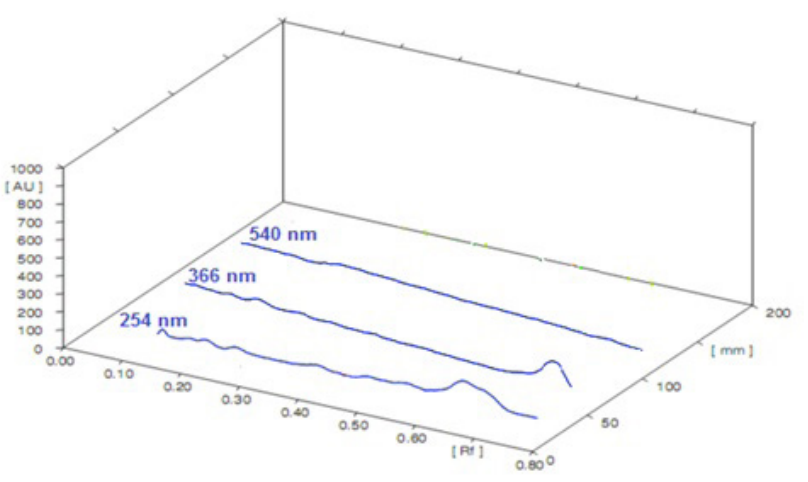

Figure 2: Overlay of 3D Display of chromatograms at $254 \mathrm{~nm}$, $366 \mathrm{~nm}$ and $540 \mathrm{~nm}$ for Alkaloids.

height at $254 \mathrm{~nm}, 366 \mathrm{~nm}$ and $540 \mathrm{~nm}$. Two unknown alkaloids, six unknown flavonoids and four unknown saponins were detected at different wavelengths having different Rf values. Those need to be studied further for their structure and characteristics. Most suitable 


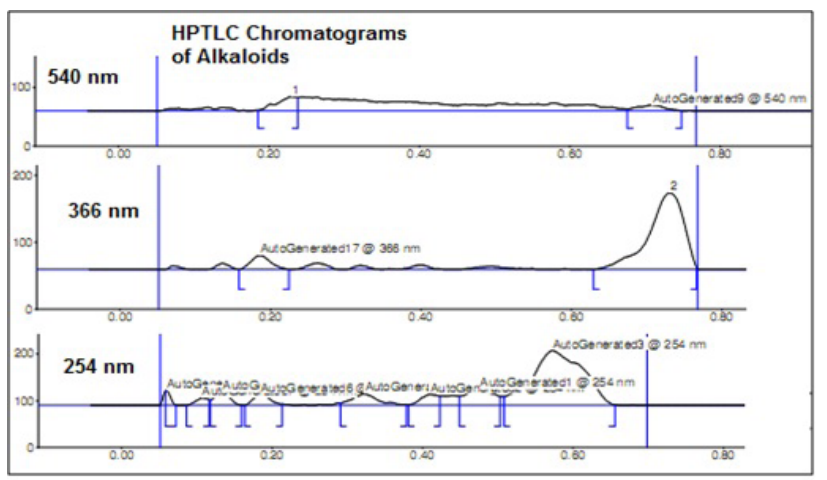

Figure 3: HPTLC Chromatograms of hydro-alcoholic extract of E. scaber at $254 \mathrm{~nm}, 366 \mathrm{~nm}$ and $540 \mathrm{~nm}$ for Alkaloids.

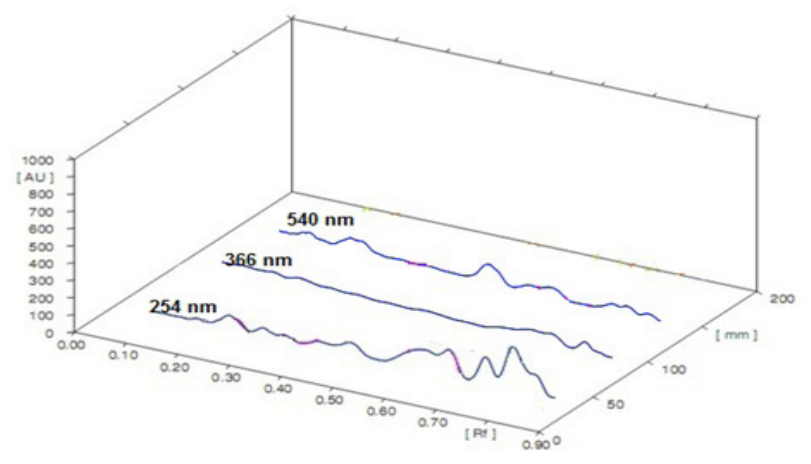

Figure 4: Overlay of 3D Display of chromatograms at $254 \mathrm{~nm}$, $366 \mathrm{~nm}$ and $540 \mathrm{~nm}$ for Flavonoids.

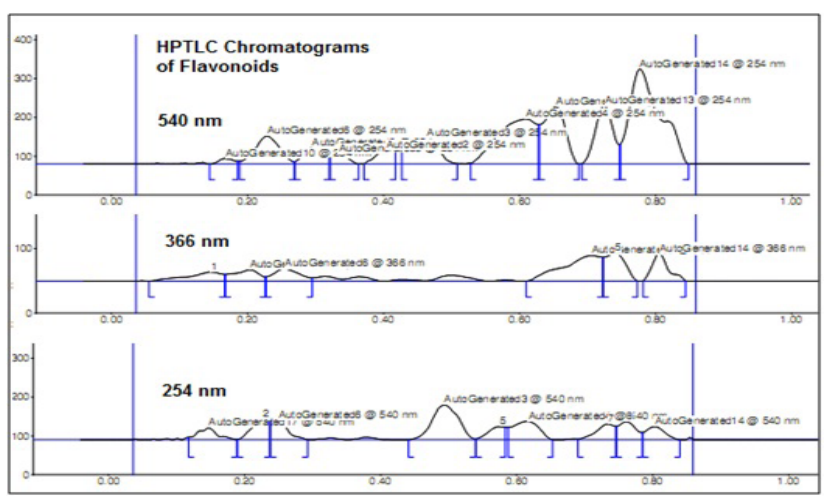

Figure 5: HPTLC Chromatograms of hydro-alcoholic extract of $E$. scaber at $254 \mathrm{~nm}, 366 \mathrm{~nm}$ and $540 \mathrm{~nm}$ for Flavonoids.

solvent system with which satisfactory separation was observed was Toluene: Ethyl acetate: Diethyl amine (7:2:1), Ethyl acetate: Formic acid: Glacial acetic acid: Water (10:0.5:0.5:1.3) and Chloroform: Acetic acid: Methanol: Water (6.4:3.2:1.2:0.8) for alkaloids, flavonoids and saponins respectively. Outcome of the present study supports the traditional claims regarding usage of selected plant due to presence of various bioactive

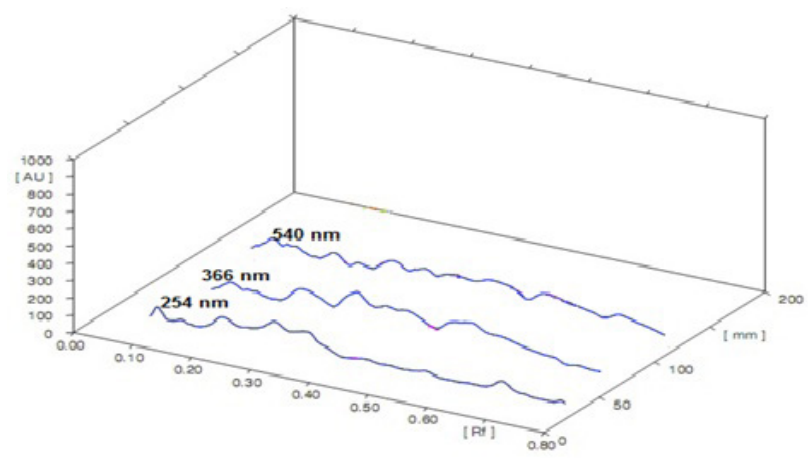

Figure 6: Overlay of 3D Display of chromatograms at $254 \mathrm{~nm}$, $366 \mathrm{~nm}$ and $540 \mathrm{~nm}$ for Saponins.

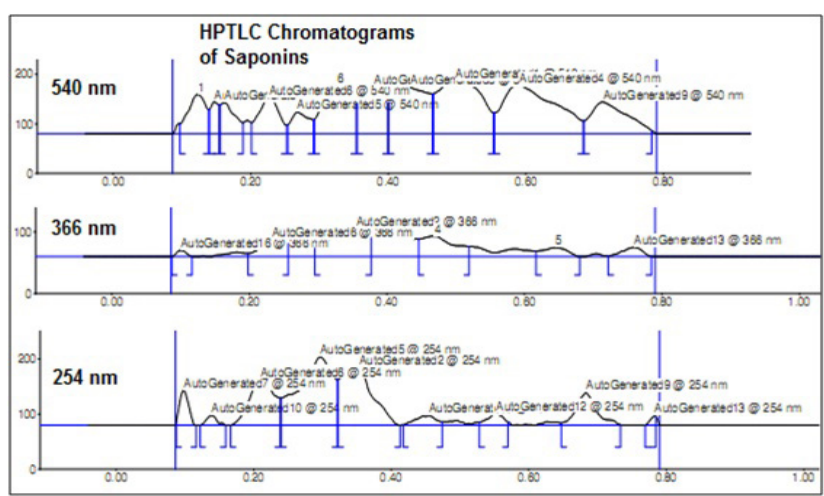

Figure 7 : HPTLC Chromatograms of hydro-alcoholic extract of E. scaber at $254 \mathrm{~nm}, 366 \mathrm{~nm}$ and $540 \mathrm{~nm}$ for Saponins.

compounds. Separation and identification of these compounds maybe used for development and formulations of new drugs for human benefit. HPTLC fingerprint profiling serves as an important phyto chemical marker and a valid estimation of genetic variability in plants. HPTLC technique was found to be simple, precise, economic and valuable tool for accurate identification and standardization of natural resources and natural products. The HPTLC fingerprint images can be stored and used as reference for further study of this plant. ${ }^{19}$

\section{CONCLUSION}

From the study carried out and adaption of HPTLC techniques by various pharmacopoeias such as USP-2007, Chinese Pharmacopoeia approves a clear recognition of this method in drug profiling, it can be concluded that HPTLC is the technique of choice for undertaking analysis of numerous complex mixtures of natural product extract as well as finished goods. It will be 
useful in determining the usefulness of natural product and quality control of the same.

\section{CONFLICTS OF INTEREST}

We wish to declare that there are no conflicts of interest associated with this publication.

\section{REFERENCES}

1. Chitlange SS, Bhujbal S, Kulkarni AA, Kulkarni $P$, Imran $M$. "A Chromatographic fingerprint analysis for herbal medicine-A quality control tool", Pharmaceutical Reviews. 2008;6(2).

2. Sheridan H, Krenn L, Jiang R, Sutherland I et al. The potential of metabolic fingerprinting as a tool for the modernisation of TCM preparations. Journal of Ethnopharmacology. 2012;140(3):482-91. http://dx.doi.org/10.1016/j. jep.2012.01.050 ; PMid:22338647

3. Uma C, Gomathi D, Ravikumar G, Kalaiselvi M, Vidya B. HPTLC fingerprinting analysis of Evolvulus alsinoides L. Journal of Acute Medicine. 2012;20(3):1-6.

4. Mehta M, Satija S, Garg M. Comparison between HPLC and HPTLC densitometry for the determination of 11 -keto- $\beta$-boswellic acid and 3- acetyl11-keto- $\beta$-boswellic acid from Boswellia serrata extract. Indian Journal of Pharmaceutical Education and Research. 2016; 50(3):418-23. http://dx.doi. org/10.5530/ijper.50.3.15

5. Marcello Nicoletti. HPTLC fingerprint: a modern approach for the analytical determination of Botanicals. Brazilian Journal of Pharmacognosy, 2011;21(5):818-23. http://dx.doi.org/10.1590/s0102-695x2011005000131

6. Nadkarni AK. Indian Materia Medica. Dhootapapeshwar Prakashan Ltd., Mumbai. 1954. ; PMid:13199797
7. Kirtikar KR, Basu BD. Indian Medicinal Plants. Periodical Experts Book Agency, Delhi. 1991

8. Chopra RN, Nayar SL, Chopra IC. Glossary of Indian Medicinal Plants. CSIR, Delhi. 1956.

9. Jog SK. 'Sahyadris - Flora and Ethnobotany Report.' William L. Brown Fellowship 2007-2008. The University of Texas at Tyler. 2009.

10. Kokate CK. Practical Pharmacognosy - Evaluation of Crude Drugs. 9th ed. Pune: Nirali Prakashan; 2000;122-124.

11. Kokate CK. Practical Pharmacognosy - Techniques and Experiments. 9th ed. Pune: Nirali Prakashan; 2002;149-153.

12. WHO, Geneva; Quality control methods for medicinal plant materials. Authorized reprint. Delhi: A.I.B.T.S. Publishers and Distributors (Regd.);28-30.

13. Khandelwal KR. Practical Pharmacognosy, Techniques and Experiments. 22nd ed. Pune: Nirali Prakashan; 2012;23:1-25

14. Harborne JB. Phytochemical Methods, 3rd ed. London:Chapman and Hall; 1998.

15. Wagner H, Baldt S, Zgainski EM. Plant drug analysis. Berlin: Springer; 1996. http://dx.doi.org/10.1007/978-3-642-00574-9

16. Newman DJ, Cragg GM. Natural Products as Sources of New Drugs over the Last 25 Years. J Nat Prod. 2007;70(3):461-77. DOI:10.1021/np068054v http://dx.doi.org/10.1021/np068054v

17. Rajkumar T, Sinha BN. Chromatographic finger print analysis of budmunchiamines in Albizia amara by HPTLC technique. Int J Res Pharm Sci. 2010;1(3):313-6.

18. Bobby Md. N, Wesely EG, Johnson M. High performance thin layer chromatography profile studies on the alkaloids of Albizia lebbeck. Asian Pacific Journal of Tropical Biomedicine. 2012;S1-6. www.apjtb.com/ zz/2012s1/1.pdf http://dx.doi.org/10.1016/S2221-1691(12)60119-1

19. Singh $\mathrm{M}$ et al. In-vitro antioxidant activity and HPTLC analysis of Borago officinalis Linn. Indian Journal of Pharmaceutical Education and Research. 2013;47(4):24-30. http://dx.doi.org/10.5530/ijper.47.4.4

\section{SUMMARY}

- HPTLC fingerprint profile of hydro-alcoholic extract of E. scaber was developed.

- The HPTLC chromatogram of hydro-alcoholic extract of E. scaber resolved 12 alkaloids, 25 flavonoids and 26 saponins with different $\mathrm{Rf}$ values including some unknown.

- Chemical profiling of selected plant is suggestive of several known and unknown bioactive molecule having potential therapeutic efficacy.

- HPTLC fingerprint analysis is useful in exact identification of plant material.

- It serves as a significant tool in differentiating adulterants and biomarker in herbal drug industry.

\section{About Authors}

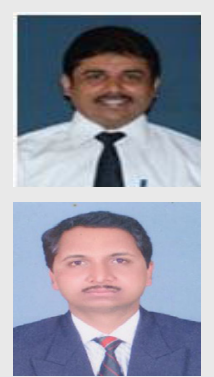

Sunil S. Jalapure: Professor, Department of pharmacognosy, K.L.E. University's College of Pharmacy, Belagavi-10, Karnataka, INDIA.

Ravindra Hiremath: Research Scholar, Department of pharmacognosy, K.L.E. University's College of pharmacy, Belagavi-10 Karnataka, INDIA.

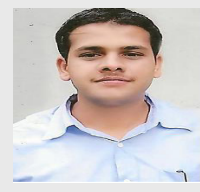

Shriram Pethakar: Department of pharmaceutical Biotechnology, KLE University's College of Pharmacy, Belagavi-10, Karnataka, INDIA. 